\title{
Saftey System for Aquatic Transportation
}

\author{
Nithya M B ${ }^{1}$, Seethal Sasindran ${ }^{2}$, Sowmya Shaju ${ }^{3}$, Sreelakshmi K M ${ }^{4}$, Melita $P T^{6}$, Bency Varghese $A^{6}$ \\ UG Scholar, Electronics and Communication, IES College of Engineering, Thrissur, India 1, 2, 3, 4,5
}

Asst. Professor, Electronics and Communication, IES College of Engineering, Thrissur, India ${ }^{6}$

\begin{abstract}
River navigation is the oldest means of transportation devised by humans. In inland waterways and in coastal protected areas even small boats have major role in transportation. The design proposal presented here is aimed at the implementation of 'an advanced safety enhancement and real time tracking system for boats which utilizes the latest tracking and safety features possible with today's electronics. The entering of the persons to boat is restricted with the maximum number of person. If the maximum number is exceeded, then the engine will not start. Also the engine can start only by an authorized person for which a finger print authentication module is used. Using an RFID reader, we will make sure availability of sufficient life jackets. If the boat crosses the border then driver will be alerted by the GSM module. If any obstacles are near the boat, then the alarm signal will warn. In critical situations like high water levels caused by unwanted turbulence/tilt or other issues, number of passengers, a critical message will be sent to the control centre along with the boat location information. Using GSM, information is send to the control room at definite intervals of time. Or the driver itself could send emergency information by pressing an emergency switch. It also uses two interconnected water tanks which will be used to balance the structure whenever a deviation to a particular side will be detected. Boat tilting is identified by using MEMS accelerometer.
\end{abstract}

Keywords: IR, RFID, GPS, GSM, MEMS.

\section{INTRODUCTION}

In this modern, fast moving and insecure world, it has become basic necessity to be aware of one's safety. For over several decades or over a century, humans are trying to include some form of safety measures in the available transportation and navigational systems. Even though river navigation is the oldest means of transportation devised by humans, and which has served as the mainstay during the initial settlement and development of civilizations, the modern technologies have somewhat omitted or have little addressed this ancient transportation system in their road map. The design proposal presented here is aimed at the implementation of 'an advanced safety enhancement and real time tracking system for boats (possibly every kind of water transportation systems) which utilizes the latest tracking and safety features possible with today's electronics.

The features incorporated in the system are a real time emergency messaging system, a load detection system-counting system, a boat tilt identification module. The data received from all these sensors will be stored internally. At definite intervals of time, this information will be messaged to the boat traffic control station, so that the information will be intact, even if some mishap occurs to the boat and the internal storage system. The system that functions as a tracking and a security system have been designed that uses main underlying concept which is GPS (Global Positioning System). This system can deal with both place and security. The VMSS (Vehicle Monitoring and Security System) is a GPS based vehicle tracking and system that is used for security applications as well.

The entering of the person to the boat will be restricted with the maximum number of persons. If the maximum number exceeds, then the alarm signal will turn $\mathrm{ON}$ and the engine will not start. If the person's count is normal, then only the engine will be ON. The entering of the person is restricted without lifejacket. A person can enter into the boat with a lifejacket only. This is made sure using RFID. Also, the engine can start only by any authorized person. If the person's finger print data match with the data that has been stored, then only the engine can start.

If the boat crosses the border of any restricted area then it checks the data coming from GPS and is alerted. Any obstacles near the boat are signalled using an alarm. In critical situations like high water levels caused by unwanted turbulence/tilt or other issues, number of passengers, a critical message will be sent to the control centre along with the boat location information, so the rescue/ recovery team may be dispatched immediately. Also the driver itself could send emergency information by pressing an 'Emergency switch'. A highlighting feature of above system is the automated rescue operation upon unwanted turbulence/tilt. Here it uses two interconnected water tanks which will be used to balance the structure whenever a deviation to a particular side will be detected (water pumps automated by the micro controller). This will make the weight even at both sides so that the boat will come to its normal position. The theory is that any excess weight at one side will be compensated with the creation of a similar and nearly equal weight at the other side also, or in other words the excess weight will be transferred to the other side making it even on both sides. 


\section{IJIREEICE \\ International Journal of Innovative Research in Electrical, Electronics, Instrumentation and Control Engineering \\ ISO 3297:2007 Certified \\ Vol. 5, Issue 4, April 2017}

\section{BLOCK DIAGRAM}

The block diagram explains the principle parts or functions of the system. The system has two sections - a boat section and a control room section. The microcontroller used in boat section is AT89c52. It is an 8 bit microcontroller. Other main components used are GPS, GSM, IR circuit, RFID reader, ultrasonic sensor, level converter IC, MEMS accelerometer etc. We use a mobile phone as control section.

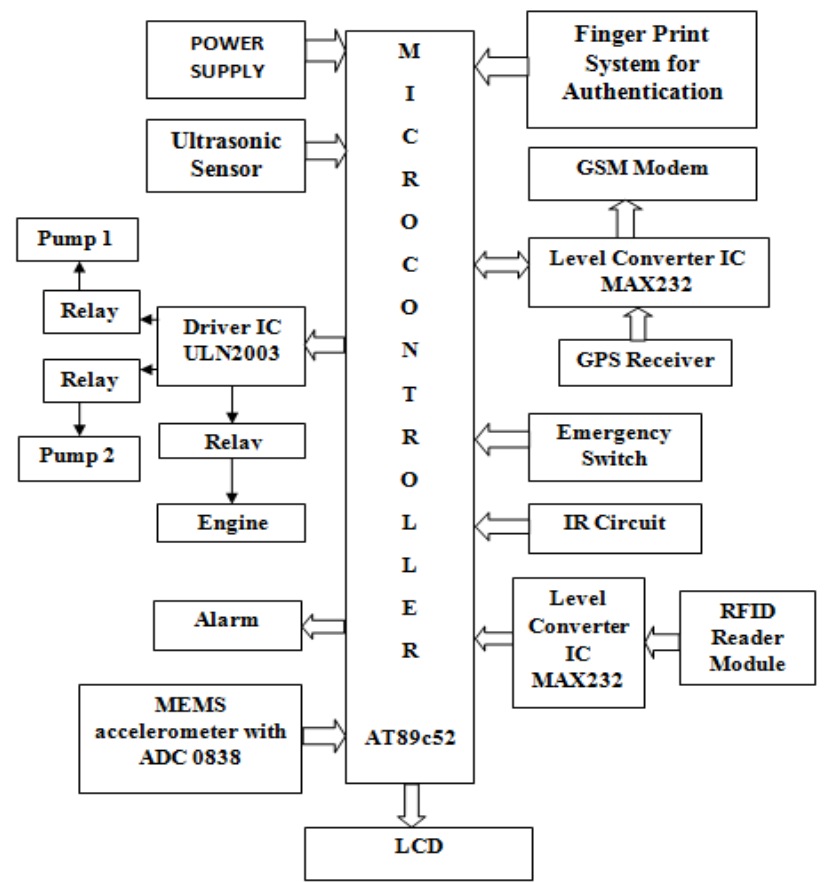

Fig. 1 Block diagram of proposed system

Control room is used for monitoring the position of boat and receiving emergency messages. Here we use a mobile phone as the control room.

\section{III.BLOCK DESCRIPTION}

\section{A. Microcontroller}

The main part of the system is the microcontroller AT89c52. All the processes and control actions are done by the microcontroller. The peripheral features of microcontroller include 4 ports, 2 timers, 6 interrupt and one serial port.

\section{B. IR circuit}

The IR circuit is used to detect, the person's count entering into the boat. The IR sensor includes two set of circuits, which is used for detecting the entering and exit of persons. The IR sensor module includes an IR led and a photo transistor. The IR led emits IR rays continuously, which falls on the photo transistor. When there is any objects in between then the rays do not falls on the photo transistor, then a high signal generate on the photo transistor. It is then taken into the microcontroller.

\section{RFID module}

The RFID reader module is used for checking the life jackets. The RFID tags which are stick on the life jacket are shown on the reader. The reader will read the information and allow the entrance of passagenger. The RFID reader module will interface with the microcontroller is through a level converter IC named MAX232. The RFID Reader module has RS232 logic, but the microcontroller has TTL logic. For the conversion of these two logics, MAX232 is used.

D. GPS modem

The GPS Modem is used for tracking the position data from the satellite. For each position, there will be a longitudinal and latitudinal data. This data will be received by the GPS Modem and is given to the microcontroller. The microcontroller will process the data and checks whether it is the border data. If it is, then the indication signal is given. 


\section{E. GSM modem}

The GSM Modem is used for sending the alert information to the control room. Also the system is used to identify the position of the boat, from the control room. When a command is transferred from the control room, then corresponding position is send back to the control room. These informations are send and received through the GSM Modem.

\section{F. Level Converter}

The level converter is used for the level conversion between the microcontroller and GSM Modem and also the GPS Modem with the microcontroller. The microcontroller has TTL logic level and the GSM modem and GPS Modem have RS232 logic level. For the conversion of these two logic levels the level converter is used. Here we use the level converter IC MAX232.

\section{G. Driver IC}

The boat engine will interface with the microcontroller through the driver IC. The signal from the microcontroller is low voltage with respect to the engine. The signal from the microcontroller is fed into the driver IC. The driver IC then amplifies the signal and is fed to the engine. The engine will control with the microcontroller. The relay is also interfaced to the microcontroller through driver IC.

\section{H. Finger Print Sensor}

The finger print sensor is used for authentication. If the person is authorized, then only he can start the engine. The fingerprint sensor is combination of R305 FP+PIC MCU board that can read different fingerprints and store in its own flash memory. The sensor can perform three functions namely Add (Enroll), Empty Database or Search Database and return the ID of stored fingerprint.

\section{IV.SIMULATION RESULT}

The circuit diagram for IR circuit was drawn in software named proteus deisgn suite and simulated by connecting the program written in keil microvision software using Embedded C.

At first the LCD is set to show the display 'SAFETY SYSTEM'. The program was written in Embedded C. A corresponding diagram was drawn in proteus design suite. The program was connected with the circuit. When it is run the corresponding display is shown in LCD. This is shown in the Fig. 2.

Similarly, program for counting the persons entering the boat is written and corresponding circuit was also drawn. Simulations were done to check the proper working. Here we set threshold value for maximum count as 20 . When we run the program we use switches to indicate the entry of any person.

By pressing the switch it is considered as the entry of a person. Green led will turn ON till the threshold value. Above the threshold value red led will turn ON. Here led is used instead of engine. So if red led is lit it indicates that the engine will not start as persons' count is above threshold value.

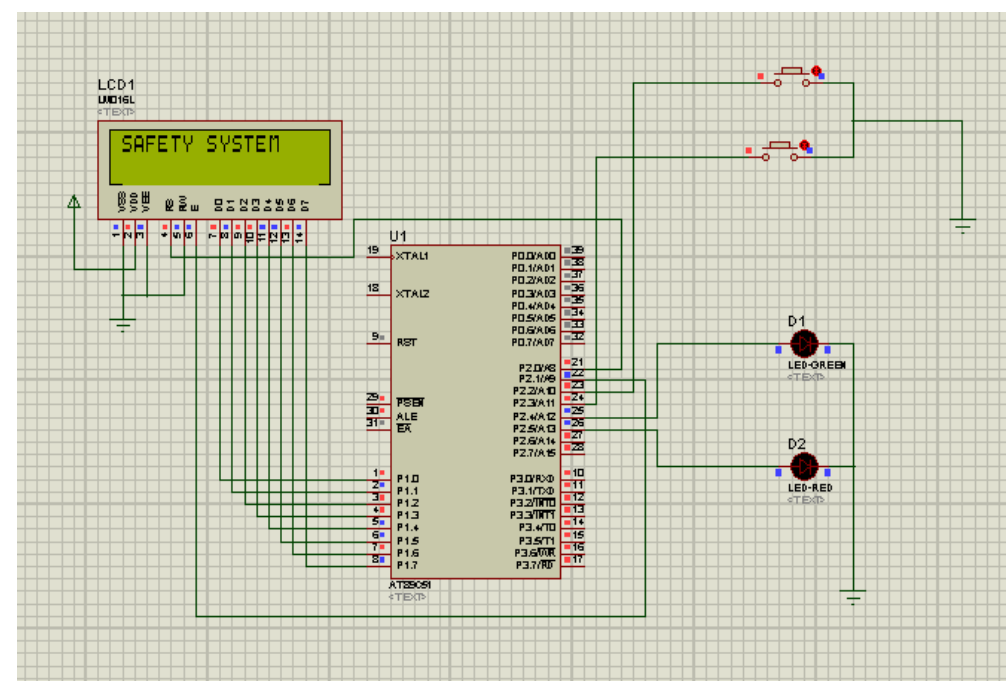

Fig. 2 LCD display showing 'SAFETY SYSTEM' 
IJIREEICE

Vol. 5, Issue 4, April 2017

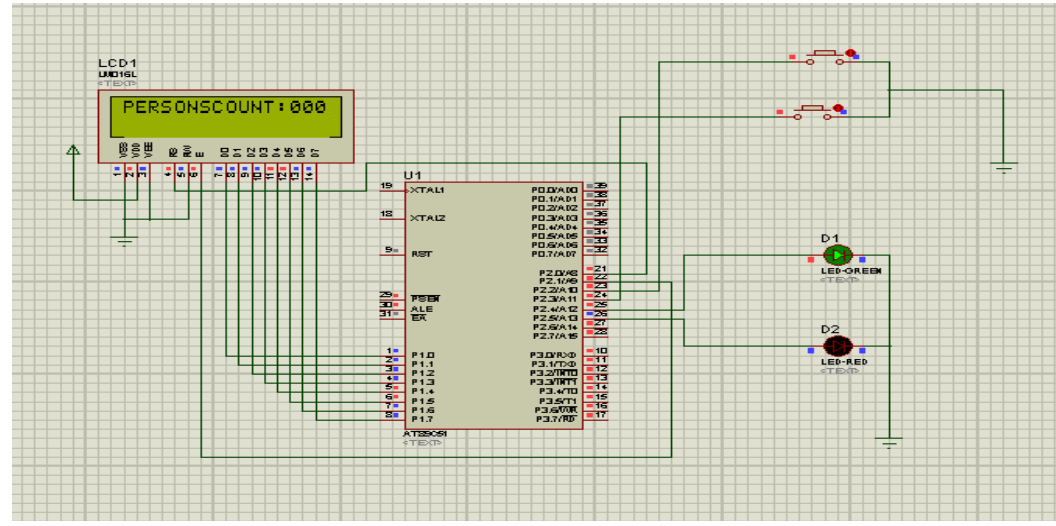

Fig. 3 Display showing person's count as 0

The different simulation results are shown in the following figures.

Fig. 3 shows the initial count as 0 . Since it is below threshold value the green led is ON.

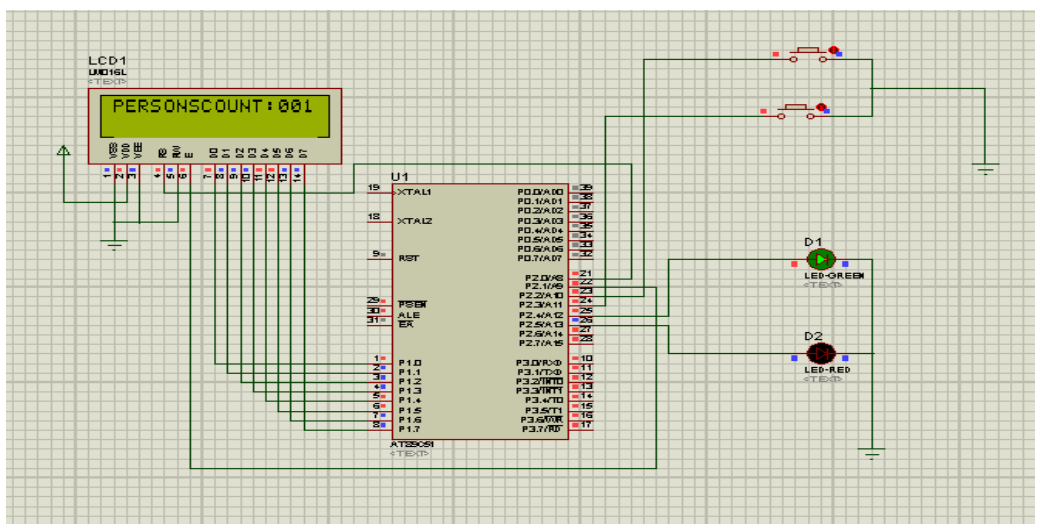

Fig. 4 Display showing person's count as 1

Fig. 4 shows the initial count as 1 . Since it is below threshold value the green led is ON.

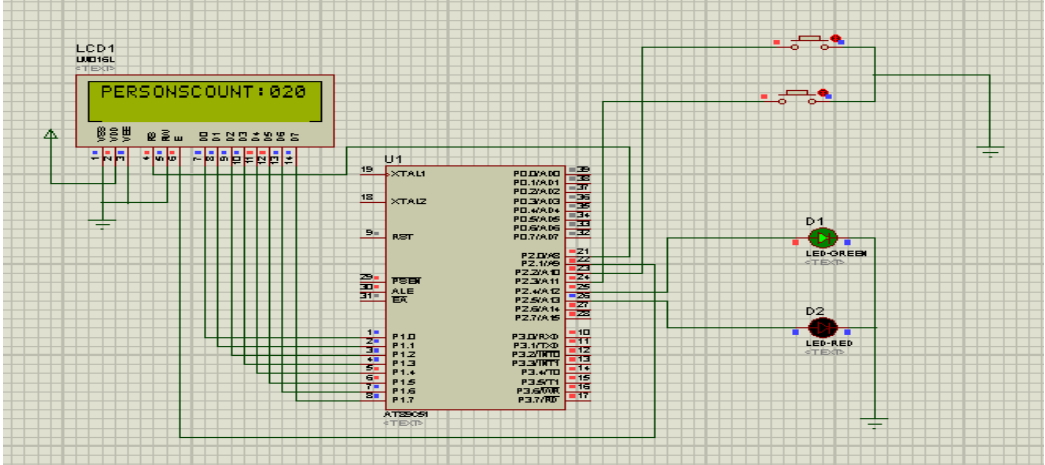

Fig. 5 Display showing person's count as 20

Now if the count become above the threshold value green led turns OFF and red led turns ON. This shows that the engine will not start if the person count is above the preset threshold value. This indicates that the program is correct and the circuit drawn is proper. The desired result was obtained by simulating the circuit drawn and the program written. Here we use a led to indicate the engine. The engine turns ON only if the number of passengers is less than the threshold value of maximum number possible. Fig. 7 shows the message received by the control room through GSM modem in different conditions. It shows the alert message send from boat in emergency situation. It contains an emergency message send by the driver. Message shows the boat number and the current position of boat. By getting the message control section can send rescue team immediately to that place where boat has stopped. The other message is border alert message. When boat exceeds the border, automatically message will transferred to control section with position details. 


\section{IJIREEICE \\ Vol. 5, Issue 4, April 2017}

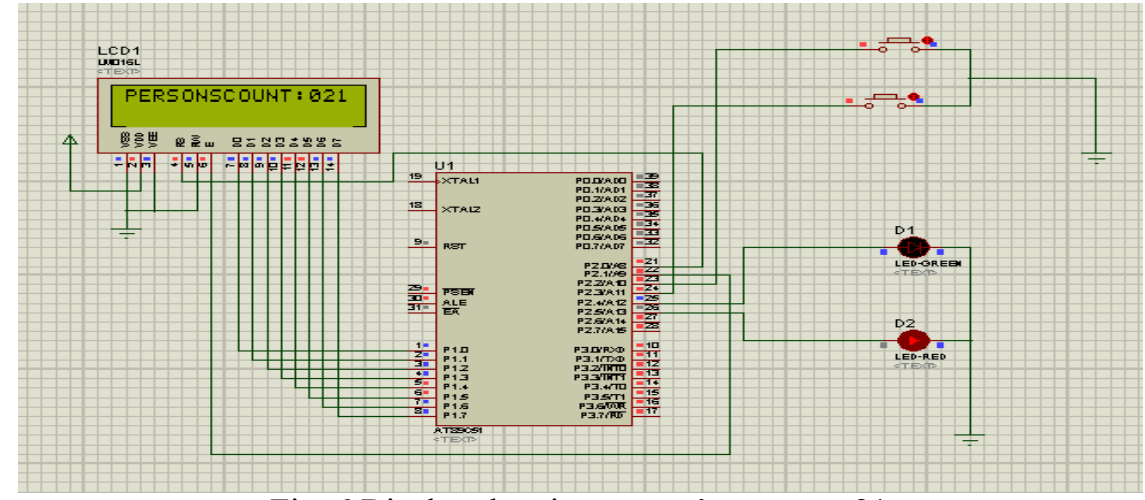

Fig. 6 Display showing person's count as 21

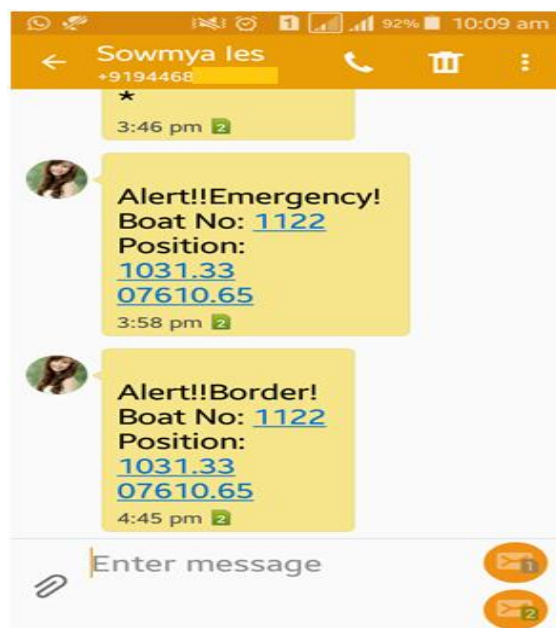

Fig. 7 Alert messages send from boat to control room

\section{ADVANTAGES}

This is an advanced safety enhancement and real time tracking system for boats. It grants adequate safety for the tourists. It consumes less power and it is highly reliable. This system is more advantageous because it can be work in any weather conditions. Use of GPS allows accurate determination of location. The security system implemented in this system is helpful to eradicate hijack of the ship by the pirates and also lost ship wrecks due to natural calamities can be identified.

\section{DISADVANTAGES}

The GPS signals are sometimes not accurate due to extreme atmospheric conditions such as geomagnetic storms and in that case we need to carry a backup map and directions. Using the fingerprint scanner does not take into consideration when a person physically changes. Changes in nature such as temperature, weight, air turbulence influence ultrasonic reaction.

\section{APPLICATIONS}

- This system can also be used in ships.

- Lifejacket system implemented here can also be used in water skiing.

- By using the technology used, the Location of any lost vehicle could be found.

- Providing a system that will alert the fishermen well in advance about the border line.

\section{CONCLUSION}

The system was implemented as an advanced safety enhancement and real time tracking system for boats using modern technology. It offers adequate safety for the tourists. In this paper, we introduce a new safety system which helps to provide high security for aquatic transportation. 


\section{IJIREEICE \\ Vol. 5, Issue 4, April 2017}

\section{ACKNOWLEDGMENT}

The authors would like to acknowledge the Management, Principal, Head of the department, all the faculties and staff of Electronics and Communication Department, of IES College of Engineering, Thrissur, Kerala, for their co-operation and technical guidance given during the entire course of the project work to complete it successfully. We would like to thank all our beloved classmates, friends and family for their encouragement.

\section{REFERENCES}

[1] Arunvijay D, Yuvaraj E, "Design of Border Alert System for fishermen using GPS", International Journal of Students Research in Technology \& Management, vol.2, No.02, March-April 2014.

[2] Naveen Kumar.M, Ranjith.R, "Border alert and smart tracking system with alarm using dgps and gsm", International Journal of Emerging Technology in Computer Science \& Electronics (IJETCSE) ISSN: 0976-1353 Volume 8 Issue 1 -APRIL 2014.

[3] Jerrin Wilsonn, Jisha K.S, Jeneese Joseph, Scaria Abraham, Janahanlal P. Stephen, “Anti-tilting system and protective measures on small scale boats", International Journal of Research in Engineering \& Advanced Technology, Volume 2, Issue 2, Apr-May, 2014 ISSN: 2320 - 8791.

[4] Jim Isaac D, Eugene Kingsley H, "Advanced border alert system u sing GPS and with intelligent Engine control unit", International Journal of Electrical and Computing Engineering (IJECE) ISSN (Online): 2349-8218 vol.1, June 2015.

[5] David Calcutt, Fred Cowan \& Hassan, '8051 Microcontrollers - an application based introduction', Newnes - Elsevier, Indian Reprint 2008

[6] Muhammad Ali Mazidi, Janice Gillispie Mazidi and Rolin D Mckinlay, 'The 8051 Microcontrollers and Embedded Systems using Assembly and C', $2^{\text {nd }}$ edition PHI Publishers.

\section{BIOGRAPHIES}

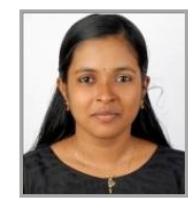

Nithya M B currently pursuing the Bachelor's degree in Electronics and Communication Engineering from the IES College of Engineering, Thrissur.

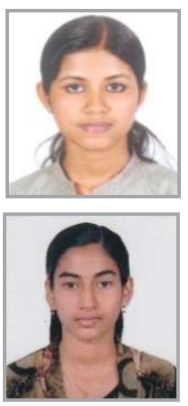

Seethal Sasindran currently pursuing the Bachelor's degree in Electronics and Communication Engineering from the IES College of Engineering, Thrissur.

Sowmya Shaju currently pursuing the Bachelor's degree in Electronics and Communication Engineering from the IES College of Engineering, Thrissur.

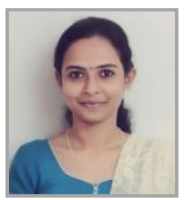

Sreelakshmi K $\quad \mathbf{M}$ currently pursuing the Bachelor's degree in Electronics and Communication Engineering from the IES College of Engineering, Thrissur.

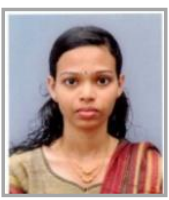

Melita P T currently pursuing the Bachelor's degree in Electronics and Communication Engineering from the IES College of Engineering, Thrissur.

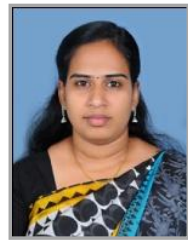

Bency Varghese A completed Master's Degree in VLSI and Embedded Systems from CUSAT. She is currently working as Assistant Professor in Department of Electronics and Communication Engineering, IES College of Engineering, Thrissur. 